EXTENDED REPORT

\title{
Risk factors for subclinical atherosclerosis in a prospective cohort of patients with systemic lupus erythematosus
}

\author{
A Doria, Y Shoenfeld, R Wu, P F Gambari, M Puato, A Ghirardello, B Gilburd, S Corbanese, \\ M Patnaik, S Zampieri, J B Peter, E Favaretto, L laccarino, Y Sherer, S Todesco, P Pauletto
}

Ann Rheum Dis 2003;62:1071-1077

See end of article for authors' affiliations

Correspondence to: Dr A Doria, Division of Rheumatology, University of Padova, Via Giustiniani, 2, 35128 Padova, Italy; adoria@unipd.it

Accepted 5 March 2003

\begin{abstract}
Objective: To evaluate traditional and non-traditional risk factors for subclinical atherosclerosis in systemic lupus erythematosus (SLE).

Methods: A prospective cohort of 78 patients with SLE without overt atherosclerotic disease was studied. SLE clinical and laboratory parameters, disease activity and damage, treatment and traditional risk factors for atherosclerosis were evaluated. At baseline (T1) and after five years' follow up (T2), the serum levels of anti-oxidised palmitoyl arachidonoyl phosphocholine (oxPAPC), anti-heat shock protein 65, and anti- $\beta_{2}$ glycoprotein I antibodies and C reactive protein were tested. At T2, intima-media thickness (IMT) was measured using duplex carotid sonography. Thickened intima, plaque, mean IMT (m-IMT), and maximum IMT (M-IMT) were assessed.

Results: A thickened intima was seen in $22 / 78$ (28\%) patients and plaque in $13 / 78$ (17\%). M-IMT and mIMT were (mean (SD)) $0.77(0.34) \mathrm{mm}$ and $0.55(0.15) \mathrm{mm}$, respectively. Patients with carotid abnormalities were significantly older, had higher blood pressure and total serum cholesterol levels, and had taken a higher prednisone cumulative dosage than those without any lesions. The carotid abnormalities were associated with renal disease and ECLAM $>2$ at $\mathrm{T1}$, and with azathioprine treatment. In multivariate analysis, age and cumulative prednisone dose were associated with carotid abnormalities; age, hypertension, and anti-oxPAPC at T2 were correlated with higher M-IMT and m-IMT.

Conclusions: In patients with SLE some non-traditional risk factors for atherosclerosis were identified, the most important of which was the cumulative prednisone dose. The role of some traditional risk factors, such as age and hypertension, was also confirmed. The predictive value of the new immunological and inflammatory markers of atherosclerosis seems to be masked by some disease related features.
\end{abstract}

$\mathrm{P}$ remature atherosclerosis in systemic lupus erythematosus (SLE) was first noted in necropsy studies reported by Bulkley and Roberts in $1975^{1}$ and subsequently confirmed in a survival study by Urowitz et al in $1976 .{ }^{2}$ Since then early clinical ${ }^{3-6}$ and subclinical ${ }^{7-10}$ atherosclerotic features have been demonstrated in SLE by several groups. Because premature atherosclerosis cannot be explained by the Framingham risk factors alone, ${ }^{3711} 12$ it has been attributed to complex interactions between traditional risk factors and factors associated with the disease itself or its treatment. ${ }^{8} 91314$

In recent years there has been a growing interest in the hypothesis that atherosclerosis may be an immune-inflammatory disease ${ }^{15}{ }^{16}$ as demonstrated by the observation of $\mathrm{T}$ cells, monocytes transforming into lipid laden foam cells, and immunoglobulin deposition within lesions.

It has also been noted that increased $\mathrm{C}$ reactive protein (CRP) levels are a major predictor of cardiovascular disease (CVD) in apparently healthy subjects. ${ }^{17}$ Moreover, some autoantibody systems including anti-heat shock protein 65 (HSP65), anti-oxidised low density lipoprotein (oxLDL), and anti- $\beta_{2}$-glycoprotein I $\left(\beta_{2} \mathrm{GPI}\right)$ seem to have a role in atherogenesis. ${ }^{18}$ In this regard, SLE is an intriguing model because it represents an inflammatory disease of autoimmune origin.

However, the role of each traditional and non-traditional risk factor in SLE is still being debated and prospective studies are lacking. ${ }^{13} 19$

Our study was designed to evaluate the role of factors associated with the development of atherosclerosis in a group of patients with SLE without overt atherosclerotic disease who had been followed up prospectively. As a surrogate measure of atherosclerosis we considered the carotid lesions evaluated by B mode ultrasound. This technique provides an accurate measurement of subclinical atherosclerosis. ${ }^{20}$ In fact, people with asymptomatic carotid abnormalities are at an increased risk for CVD. ${ }^{21}$

\section{PATIENTS AND METHODS}

Study group

The study subjects consisted of all patients with SLE meeting the American College of Rheumatology (ACR) criteria ${ }^{22}$ seen at the Division of Rheumatology, University of Padova, Italy, who had no evidence of overt atherosclerotic disease at the baseline evaluation. Specifically, patients with angina, myocardial infarction, congestive heart failure due to coronary heart disease, transient ischaemic attack, or stroke before the start of the study were excluded.

During the five year follow up they were regularly monitored for clinical and laboratory parameters, including traditional risk factors for atherosclerosis, and data were

\footnotetext{
Abbreviations: aCL, anticardiolipin antibody; $\mathrm{ACR}$, American College of Rheumatology; aPL, antiphospholipid antibody; $\beta_{2} \mathrm{GPI}, \beta_{2^{-}}$ glycoprotein I; BP, blood pressure; CRP, C reactive protein; CVD, cardiovascular disease; ELISA, enzyme linked immunosorbent assay; HSP 65, heat shock protein 65; IMT, intima-media thickness; LA, lupus anticoagulant; LDL, low density lipoprotein; m-IMT, mean intima-media thickness; M-IMT, maximum intima-media thickness; oxPAPC, oxidised palmitoyl arachidonoyl phosphocholine; SLE, systemic lupus erythematosus
} 
collected according to a standard protocol. At the five year follow up evaluation all patients underwent an echo colour Doppler (duplex) carotid ultrasound examination.

The study was approved by the local ethics committee. All patients gave informed consent.

\section{Variable measurements}

SLE related risk factors

All prominent clinical and laboratory features, registered at the baseline and after five years' follow up, were considered. For definitions of features specific to SLE, including renal disease, we used those included in the ACR criteria. ${ }^{22}$

Antinuclear antibodies and anti-double stranded DNA antibodies (anti-dsDNA) were detected by indirect immunofluorescence using as a substrate HEp-2 cells and Crithidia luciliae, respectively. Anti-extractable nuclear antigen antibodies were tested by counterimmunoelectrophoresis, anticardiolipin antibodies (aCL) by an "in house" enzyme linked immunosorbent assay (ELISA) according to Harris ${ }^{23}$ and lupus anticoagulant (LA) by Russell Viper Venom Time assay.

SLE disease activity was measured by the European Consensus Lupus Activity Measurement (ECLAM) score ${ }^{24}$ and cumulative damage using the Systemic Lupus International Collaborating Clinics (SLICC) damage index..$^{25}$ An ECLAM score $>2$ was considered indicative of active disease.

Cumulative prednisone equivalent dose, as well as low dose aspirin, hydroxychloroquine, and immunosuppressant drug use, was recorded on a separate sheet at each clinical evaluation after baseline. Information on the treatment before baseline was collected from patients' medical charts.

\section{Traditional risk factors}

We considered the following variables: age, sex, total serum cholesterol, triglycerides, blood pressure, body mass index, diabetes mellitus, cigarette smoking, and family history of CVD. For all modifiable traditional risk factors we considered the mean values of the measurements obtained at each evaluation during follow up because they show not only the presence of a disorder but also its persistence over the observational period.

On the basis of the mean values, hypercholesterolaemia and hypertriglyceridaemia were defined as a total serum cholesterol $>5.2 \mathrm{mmol} / \mathrm{l}$, or a serum triglyceride $>2.26 \mathrm{mmol} / \mathrm{l}$; systolic and diastolic blood pressure (BP) were determined using an average of two consecutive sitting blood pressure readings, five minutes apart. We considered patients to be hypertensive when they had, over the study period, an average systolic BP $>140 \mathrm{~mm} \mathrm{Hg}$ and/or diastolic BP $>90 \mathrm{~mm} \mathrm{Hg}$ (according to the WHO definition) and/or when they were taking antihypertensive drugs. Body mass index was calculated from height and weight. Diabetes mellitus was defined according to WHO criteria. For cigarette smoking we divided patients into three groups: (a) never smokers; (b) ever smokers, and (c) smokers during the observational period. Finally, we considered a family history of CVD in those who had a first degree relative who had had the disease before the age of 60 .

\section{Immunological and inflammatory markers}

At baseline and after five years' follow up, a blood sample was drawn after an overnight fast. The blood samples were immediately centrifuged and sera removed and stored at $-80^{\circ} \mathrm{C}$ until analysed. Anti-oxidised palmitoyl arachidonoyl phosphocholine (oxPAPC), anti-HSP65, anti-

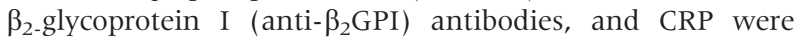
tested.

Anti-oxPAPC antibody was detected by ELISA. A synthetic phospholipid PAPC (Avanti Polar Lipids, Alabaster, Alabama) as a surrogate for the precursor of the biologically active lipid was exposed to air for 16 hours for oxidative modification. ${ }^{26}$ The oxPAPC or PAPC was coated in the plate as antigen for detection of the autoantibodies. ${ }^{27}$

The reaction was read in an ELISA reader at $405 \mathrm{~nm}$. The standard curves were derived by computer assisted data reduction with the four parameter function. SoftMax software connected a straight line between the means of calibrator replicates. Seven standards were prepared at appropriate dilutions. Arbitrary ELISA units were used for the quantitative assay. The correlation coefficient between the target and calculated values of standards was 0.998 for IgG autoantibodies against oxPAPC. Cut off value for antioxPAPC was $<10 \mathrm{U} / \mathrm{ml}$ (95th centile of the normal population).

Anti-HSP65 antibody was tested on ELISA plates coated with $100 \mu \mathrm{l} /$ well of $1 \mu \mathrm{g} / \mathrm{ml}$ HSP65 (Lionex Diagnostics and Therapeutics, Braunschweig Germany).The detection of anti-HSP65 antibodies was performed by typical ELISA using serum specimens, standards, and controls 1:200 diluted in $1 \%$ bovine serum albumin-phosphate buffered saline.

Anti- $\beta_{2}$ GPI antibody was detected by an ELISA kit (INOVA Diagnostics Inc, San Diego CA). The reaction was visualised with $3,3^{\prime}, 5,5^{\prime}$-tetramethylbenzidine as substrate and read at $450 \mathrm{~nm}$. Cut off value for anti- $\beta_{2}$ GPI was $<20 \mathrm{U} / \mathrm{ml}$ (95th centile of the normal population).

CRP was measured by nephelometry, using a CRP-UL kit (Wako Chemicals USA, Inc) Bayer ADVIA 1650 System. Cut off value for CRP was $<5 \mathrm{mg} / \mathrm{l}$ (95th centile of the normal population).

\section{Duplex ultrasonography}

Carotid arteries were evaluated using the Aspen Advanced (Acuson, USA) equipped with a linear probe $(7-10 \mathrm{MHz}$ ). The intima-media thickness (IMT) was measured as previously described. ${ }^{28}$ On end diastole images, a total of three IMT measurements on each side were taken at the following points: common carotid artery ( $10 \mathrm{~mm}$ before the bulb), bulb (5-10 mm cranially to the start of the bulb), and internal carotid artery ( $10 \mathrm{~mm}$ after the flow divider).

Mean IMT (m-IMT; the mean of the three IMT measurements on each side) and the maximum IMT (M-IMT, the highest IMT value found among the six segments studied) were assessed.

According to current sonographic criteria, we refer to "normal" IMT when complex intima-media is $\leqslant 0.9 \mathrm{~mm}$. MIMT values $>0.9 \mathrm{~mm}$ were considered indicative of thickened intima $^{29}$ and M-IMT values $>1.3 \mathrm{~mm}$ indicative of atherosclerotic plaque. ${ }^{30}$ Data for the reproducibility of our method have been reported elsewhere. ${ }^{28}$

\section{Statistical methods}

Continuous variables were averaged and values expressed as mean (SD). Differences between groups were evaluated using the two sample $t$ test for normally distributed variables. Prevalences of categorical variables were evaluated with two way contingency tables, expressed as a percentage rate, and compared by means of the Pearson $\chi^{2}$ test. The univariate correlations between m-IMT and M-IMT, and other continuous variables were evaluated by Pearson correlation coefficient with Bonferroni's adjusted probabilities. The mIMT and the M-IMT were also played into a multiple regression analysis, obtaining one multiple correlation coefficient $(r)$. The prevalence of plaque and the prevalence of thickened intima were used as categorical variables in a logistic regression analysis. The SYSTAT package was used for calculation. 


\section{RESULTS}

\section{Basic characteristics of the patients}

Of the 90 eligible patients, eight (9\%) chose not to participate in the study and four $(4.4 \%)$ were lost to follow up. Therefore, we studied 78 patients (67 female, 11 male) with a mean (SD) age at study entry of 31 (9) years, mean (SD) disease duration 4.9 (3.7) years, mean (SD) disease follow up 60.6 (9.0) months, and mean (SD) age at the time of carotid ultrasound evaluation 36 (9) years. No patients had cardiovascular events during follow up.

Table 1 summarises the prominent clinical and laboratory features at baseline and after five years' follow up. The mean (SD) cumulative prednisone equivalent dose taken by the patients was 31.7 (18.3) g. During the follow up, 22 (28\%) patients had taken low dose aspirin, 50 (64\%) hydroxychloroquine, 37 (47\%) immunosuppressant drugs, including $28(36 \%)$ azathioprine.

Mean (SD) body mass index was $23(3.6) \mathrm{kg} / \mathrm{m}^{2}$. Twenty five patients $(32 \%)$ had a body mass index $\geqslant 25$. Hypertension was diagnosed in $35(45 \%)$ patients. High levels of total serum cholesterol and triglycerides were observed in $11(14 \%)$ and $4(5 \%)$ patients, respectively. Forty seven patients $(60 \%)$ had never been smokers, 31 $(40 \%)$ had smoked before their entry into the study and/or during the follow up, and $20(26 \%)$ had smoked only during the follow up. Thirty patients $(38 \%)$ had a family history of CVD.

Table 2 reports the immunological and inflammatory parameters. The serum mean levels of anti-oxPAPC, antiHPS65, and anti- $\beta_{2}$ GPI antibodies were lower in the second sample than in the first one. However, the differences were significant only for anti-HSP65 and anti-oxPAPC antibody levels.

Ultrasound study showed a thickened intima in 22 (28\%) patients and plaque in $13(17 \%)$. In our patients mean (SD) M-IMT and m-IMT were $0.77 \quad(0.34) \mathrm{mm}$ and 0.55 (0.15) $\mathrm{mm}$, respectively.

\section{Univariate analysis of risk factors}

Patients with plaque or thickened intima compared with those without any carotid abnormalities were significantly older $(p<0.0005$ or $p<0.0005)$, and had higher systolic BP $(\mathrm{p}=0.001$ or $\mathrm{p}=0.004)$, diastolic $\mathrm{BP}(\mathrm{p}=0.017$ or $\mathrm{p}=0.002)$, and total serum cholesterol levels $(p=0.001$ or $p=0.002)$

Table 1 Prominent SLE features seen at the time of the first (baseline) and second (after five year follow up) evaluations in 78 patients enrolled in the study

\begin{tabular}{lll}
\hline SLE features & $\begin{array}{l}\text { Baseline } \\
\text { No }(\%)\end{array}$ & $\begin{array}{l}5 \text { Year follow up } \\
\text { No }(\%)\end{array}$ \\
\hline Arthritis & $9(12)$ & $6(8)$ \\
Skin rash & $12(15)$ & $10(13)$ \\
Serositis & $2(3)$ & $1(1)$ \\
Haematol. involvement & $37(47)$ & $31(40)$ \\
Renal involvement & $16(21)$ & $8(10)$ \\
CNS involvement & $3(4)$ & $2(3)$ \\
Anti-dsDNA & $37(47)$ & $35(45)$ \\
Anti-Sm & $8(10)$ & $3(4)$ \\
Anti-U1RNP & $10(13)$ & $9(12)$ \\
Anti-SSA & $27(35)$ & $22(28)$ \\
Anti-SSB & $3(4)$ & $5(6)$ \\
Anti-aCL IgG & $42(54)$ & $33(42)$ \\
Anti-aCL IgM & $12(15)$ & $17(22)$ \\
LA & $9(12)$ & $13(17)$ \\
ECLAM score $>2$ & $43(55)$ & $34(44)$ \\
SLICC DI $\geqslant 1$ & $8(10)$ & $14(18)$ \\
\hline
\end{tabular}

CNS, central nervous system; anti-dsDNA, anti-double stranded DNA antibody; anti-aCL, anticardiolipin antibody; LA, lupus anticoagulant; ECLAM, European Consensus Lupus Activity Measurement score; SLICC $\mathrm{DI}$, Systemic Lupus International Collaborating Clinics damage index. (table 3). Hypertension was more common in patients with plaque or thickened intima than in those without carotid abnormalities $(p=0.002$ or $p<0.0005)$ (table 4$)$. Moreover, both M-IMT and m-IMT were significantly higher in patients with hypertension $(\mathrm{p}<0.0005$ and $\mathrm{p}<0.0005$, respectively) (table 4).

Plaque and thickened intima were associated with baseline renal disease $(p=0.012$ and $p=0.030$, respectively), baseline ECLAM score $>2(p=0.019$ and $p=0.014$, respectively $)$, and azathioprine treatment $(\mathrm{p}=0.006$ and $\mathrm{p}=0.031$, respectively) (table 4). Plaque was also associated with cumulative prednisone intake $\geqslant 40 \mathrm{~g}(\mathrm{p}=0.033)$. The M-IMT level (table 4$)$ was higher in patients with baseline renal disease $(p=0.018)$, baseline ECLAM score $>2(p=0.033)$, and in patients who had taken a cumulative prednisone dose $\geqslant 40 \mathrm{~g}$ $(p=0.045)$ as well as azathioprine $(p=0.027)$. The m-IMT level was higher in patients with baseline ECLAM score $>2$.

Patients with plaque compared with those without any carotid abnormalities had taken a significantly higher prednisone cumulative dose even after adjusting the data for traditional risk factors (table 3).

Autoantibody and inflammatory parameter mean levels did not differ in patients with and without carotid lesions and, in addition, they did not correlate with M-IMT or m-IMT.

\section{Multivariate analysis of risk factors}

In the multivariate analysis (table 5), age and cumulative prednisone intake were associated with plaque. Age, cumulative prednisone intake and absence of hypertension were associated with thickened intima.

In decreasing order of statistical power (table 6), age, antioxPAPC serum level at the second evaluation, cumulative prednisone intake, and renal disease at baseline were associated with higher M-IMT $\left(r^{2}=0.425\right)$. Age, antioxPAPC serum levels at the second evaluation, and hypertension were associated with higher m-IMT $\left(r^{2}=0.498\right)$.

\section{DISCUSSION}

We analysed the role of traditional and disease related risk factors, including some recently proposed immunological and inflammatory parameters, in predicting subclinical atherosclerosis in a prospective cohort of 78 patients with SLE. Our main outcome-that is, subclinical atherosclerosis, was assessed cross sectionally at the end of follow up. However, owing to the young age and short disease duration of our patients at baseline, the risk of having introduced a potential bias was very low. ${ }^{29}$ It is noteworthy that the prevalence of carotid abnormalities was negligible in a control group of 27 healthy subjects with mean (SD) age of 30 (9) years who had been previously tested in our laboratory. ${ }^{28}$

We found carotid plaque in $17 \%$ and thickened intima in $28 \%$ of our 78 patients with SLE. With duplex ultrasound, carotid plaques were found in $65 \%$ of patients with SLE with previous CVD and in 38\% of those without previous CVD studied by Svenungsson et al, ${ }^{9}$ and in $40 \%, 38 \%$, and $9 \%$ of patients considered by Manzi et $a l^{7}$ Roman et $a l^{8}$ and Vlachoyiannopoulos et al, ${ }^{10}$ respectively.

However, differences in the plaque definition and in the characteristics of the groups studied may account for the result variability. Our patients were all white subjects, had no history of previous CVD, and were much younger (mean age 36 years) than the patients studied by Svenungsson et al, ${ }^{9}$ Manzi et $a l^{7}$ and Roman et $\mathrm{al}^{8}$ (mean age 52, 45, and 41 years, respectively), and a little older than those considered by Vlachoyiannopoulos et al $^{10}$ (mean age 33 years).

Along with plaque and thickened intima, we also considered the M-IMT and the m-IMT level, which are complementary but distinct risk factors for cardiovascular events. ${ }^{21}$ 
Table 2 Serum levels of immunological and inflammatory markers at baseline and after five years' follow up in the 78 patients with SLE

\begin{tabular}{|c|c|c|c|c|c|}
\hline \multirow[b]{2}{*}{ Markers } & \multicolumn{2}{|l|}{ Baseline } & \multicolumn{2}{|c|}{5 Year follow up } & \multirow[b]{2}{*}{ p Value } \\
\hline & Mean (SD) & $(95 \% \mathrm{Cl})$ & Mean (SD) & $(95 \% \mathrm{Cl})$ & \\
\hline $\begin{array}{l}\text { Anti-oxPAPC (U/ml) } \\
\text { Anti-HSP65 (U/ml) } \\
\text { Anti- } \beta_{2} \mathrm{GPI}(\mathrm{U} / \mathrm{ml}) \\
\text { CRP (mg/l) }\end{array}$ & $\begin{array}{l}15.3(31.2) \\
32.9(15.7) \\
22.2(29.2) \\
22(57)\end{array}$ & $\begin{array}{l}(8.3-22.3) \\
(29.3-36.4) \\
(15.6-28.8) \\
(9-35)\end{array}$ & $\begin{array}{l}5.1(8.0) \\
18.5(4.3) \\
18.8(35.1) \\
20(54)\end{array}$ & $\begin{array}{l}(3.3-6.9) \\
(17.5-19.5) \\
(10.9-26.7) \\
(8-32)\end{array}$ & $\begin{array}{l}0.004 \\
<0.0005 \\
\text { NS } \\
\text { NS }\end{array}$ \\
\hline
\end{tabular}

Anti-oxPAPC, anti-oxidised palmitoyl arachidonoyl phosphocholine antibody; anti-HSP65, anti-heat shock protein 65 antibody; anti- $\beta_{2} \mathrm{GPI}$, anti- $\beta_{2}$-glycoprotein I antibody; CRP, $C$ reactive protein.

In our study the strongest predictors of carotid lesions or increased M-IMT and m-IMT were age and hypertension. Moreover, we evaluated all the SLE related features at baseline and after five years' follow up. Renal disease and active disease at baseline were predictive markers of both carotid plaque and thickened intima as well as increased $\mathrm{M}$ IMT at the end of follow up. It is noteworthy that clinical features at the time of carotid ultrasound examination and antinuclear antibody, including anti-dsDNA both at baseline and after five years' follow up, were not related to any carotid abnormalities.

Very few studies have extensively examined clinical SLE features as predictors of clinical and subclinical atherosclerosis. Gladman et al found that myocarditis and pericarditis were associated with clinical coronary artery disease. ${ }^{5}$ Svenungsson et al found no relationship between plaque and disease variables, including renal disease. ${ }^{9}$ Manzi et al found an inverse relationship between disease activity measured by the SLAM score and plaque. ${ }^{7}$ However, these last two ultrasound studies are cross sectional, thus evaluating SLE features at the time of ultrasound examination.

SLAM or ECLAM scores measure disease activity at one point in time; they greatly vary as a consequence of treatment and/or disease relapse, and do not reflect the SLE activity throughout the disease course. The relationship we found between active disease at baseline and carotid lesions may be due to active renal disease in a subset of our patients. Lupus glomerulonephritis has a more relevant impact on the disease evolution than SLAM or ECLAM scores. In fact, it indicates disease severity more than activity. The occurrence of glomerulonephritis in patients with SLE requires more aggressive treatment, including higher prednisone dosage, leading to some complications like hypertension or dyslipidaemia, which are well known predictors of atherosclerosis. Nephrotic range proteinuria was a predictor of increased $M$ IMT and m-IMT in juvenile SLE. ${ }^{31}$ In the current five year prospective study, renal disease seems to be a predictor of subclinical atherosclerosis in adult patients with SLE too. At the time of ultrasound examination, glomerulonephritis was in remission in some of our patients and, consequently, the relationship between renal disease and carotid lesions at that time was no longer significant. However, it is very common to observe glomerulonephritis remission as the result of treatment. Unfortunately, the relapse of the glomerulonephritis is very common even in patients treated aggressively.

We found an association between the cumulative dose of prednisone and plaque. The relationship between corticosteroids and CVD is controversial, corticosteroids being considered as risk factors for CVD by some authors, ${ }^{4}{ }^{6}$ but not by others. ${ }^{5}$ Manzi et al, using carotid ultrasound, showed a significant association between plaque and cumulative corticosteroid dosage as well as duration of treatment. ${ }^{7}$ One major question is whether or not the effect of corticosteroids on atherosclerosis is mediated by traditional risk factors. In our study the cumulative prednisone dose remained associated with plaque after adjusting it for the classical Framingham predictors.

Azathioprine use was associated with carotid abnormalities in univariate, but not in multivariate, analysis. Azathioprine is mainly used for maintenance of remission, after cyclophosphamide induction therapy, in patients with lupus glomerulonephritis. Therefore, it might be related to renal disease.

Therefore, it is likely that the SLE features that clearly emerged as risk factors for atherosclerosis by univariate statistical analysis-that is, cumulative prednisone intake, azathioprine treatment, renal disease, and active disease at baseline, were linked to each other and all indicated a severe disease. Prednisone cumulative intake was the strongest factor and therefore entered into the multivariate best models.

Table 3 Univariate analysis of risk factors for atherosclerosis in 78 patients with SLE: continuous variables (mean (SD)) ${ }^{*}$ in patients with (yes) and without (no) carotid lesions. Only significant results are reported

\begin{tabular}{|c|c|c|c|c|c|c|}
\hline \multirow[b]{2}{*}{ Risk factors } & \multicolumn{3}{|l|}{ Plaque } & \multicolumn{3}{|c|}{ Thickened intima } \\
\hline & $\begin{array}{l}\text { Yes } \\
(n=13)\end{array}$ & $\begin{array}{l}\text { No } \\
(n=65)\end{array}$ & $p$ Value & $\begin{array}{l}\text { Yes } \\
(n=22)\end{array}$ & $\begin{array}{l}\text { No } \\
(n=56)\end{array}$ & p Value \\
\hline Age (years) & 45.7 (9.9) & $35.3(8.8)$ & $<0.0005$ & $43.3(10.6)$ & $34.6(8.2)$ & $<0.0005$ \\
\hline $\mathrm{BMI}\left(\mathrm{kg} / \mathrm{m}^{2}\right)$ & $25.0(3.3)$ & $23.2(3.3)$ & NS & $24.9(3.5)$ & $22.9(3.5)$ & 0.037 \\
\hline Total cholesterol (mmol/l) & $6.1(1.3)$ & $5.0(1.0)$ & 0.001 & $5.8(1.4)$ & $4.9(0.9)$ & 0.002 \\
\hline Triglycerides (mmol/l) & $1.8(1.2)$ & $1.4(0.7)$ & NS & $1.9(1.1)$ & $1.4(0.5)$ & 0.01 \\
\hline Systolic BP (mm Hg) & $138(16.7)$ & $124.5(12.3)$ & 0.001 & $133.8(16.1)$ & $123.9(12.1)$ & 0.004 \\
\hline Diastolic BP (mm Hg) & $86.9(7.2)$ & $80.3(9.0)$ & 0.017 & $86.3(8.1)$ & $79.5(8.7)$ & 0.002 \\
\hline PRD not adjusted (g) & $46.2(24.2)$ & $27.9(15.3)$ & 0.001 & $38.0(23.0)$ & $28.1(15.4)$ & 0.031 \\
\hline PRD Adjusted $\dagger$ (g) & $45.2(5.0)$ & 28.1 (2.09) & 0.003 & $36.1(4.05)$ & $28.9(2.4)$ & NS \\
\hline
\end{tabular}

$\mathrm{BMI}$, body mass index; $\mathrm{BP}$, blood pressure; PRD, prednisone cumulative dosage.

*For all modifiable risk factors we considered the mean values of the measurements obtained at each evaluation during follow up (see methods). †For age, BMI, systolic BP, diastolic BP, smoking, and hypercholesterolaemia. 
Table 4 Univariate analysis of risk factors in 78 patients with SLE. Only significant results are reported

\begin{tabular}{|c|c|c|c|c|c|c|c|c|c|c|c|c|c|c|}
\hline \multirow[b]{2}{*}{ Predictors } & \multicolumn{3}{|c|}{ Hypertension } & \multicolumn{3}{|c|}{ Renal disease at $\mathrm{Tl}$} & \multicolumn{3}{|c|}{$\mathrm{ECLAM}>2$ at $\mathrm{T} 1$} & \multicolumn{2}{|l|}{$P D N \geqslant 40 \mathrm{~g}$} & \multicolumn{3}{|c|}{ Azathioprine } \\
\hline & Yes & & No & Yes & & No & Yes & & No & Yes & No & Yes & & No \\
\hline Plaque (\%) & 31.4 & $\|$ & 4.6 & 37.5 & $\ddagger$ & 11.2 & 25.5 & $\ddagger$ & 5.7 & 25.6 & * 7.6 & 32.1 & $\S$ & 8.0 \\
\hline $\begin{array}{l}\text { Thickened } \\
\text { intima (\%) }\end{array}$ & 48.5 & ฯ & 11.6 & 50 & * & 22.5 & 39.5 & $\ddagger$ & 14.2 & 35.8 & 20.5 & 42.8 & * & 20.0 \\
\hline $\begin{array}{l}\text { M-IMT (mean } \\
\text { (SD) }\end{array}$ & $0.92(0.41)$ & ฯ & $0.66(0.20)$ & $0.95(0.50)$ & $\ddagger$ & $0.73(0.27)$ & $0.85(0.41)$ & * & 0.6810 .19 & $0.89(0.47)$ * & * $0.72(0.26)$ & $0.89(0.43)$ & $t$ & $0.71(0.26)$ \\
\hline $\begin{array}{l}\text { m-IMT (mean } \\
\text { (SD) }\end{array}$ & $0.63(0.18)$ & 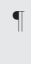 & $0.49(0.08)$ & $0.61(0.16)$ & & $0.54(0.15)$ & $0.59(0.18)$ & $\dagger$ & 0.5110 .10 & $0.57(0.17)$ & $0.55(0.15)$ & $0.58(0.16)$ & & $0.54(0.15)$ \\
\hline
\end{tabular}

T1, baseline; ECLAM, European Consensus Lupus Activity Measurement score; PDN, prednisone cumulative dose; M-IMT, maximum IMT; m-IMT, mean IMT. ${ }^{*} \mathrm{p}<0.05 ; \mathrm{\uparrow p}<0.03 ; \mathrm{fp}<0.02 ; \S \mathrm{p}=0.006 ; \| \mathrm{p}=0.002 ; \uparrow \mathrm{p}<0.0005$.

The recent hypothesis on the inflammatory and immunological nature of atherosclerosis has opened new frontiers of research and prompted us to test some new risk factors of atherosclerosis.

Among the inflammation markers, CRP has recently been shown to be a reliable predictor of cardiovascular events in populations without SLE. ${ }^{17}$ In the study of Manzi et al, ${ }^{7}$ CRP was associated with plaque in the univariate analysis, but it was not entered into the multivariate model. CRP is not a suitable inflammatory marker in $\mathrm{SLE}^{32}$ and it is not surprising that CRP levels were not associated with carotid abnormalities in our patients.
Several studies have shown that oxidation of LDL has an important role in the development of atherosclerosis. Raised titres of anti-oxLDL have been found in SLE, ${ }^{93}$ but their association with CVD is debated. ${ }^{93}$ OxPAPC has been shown to be an important antigenic epitope of oxLDL. ${ }^{26}$ OxPAPC and oxLDL have similar bioactivities. ${ }^{34}$ However, oxPAPC as an antigen is more stable than oxLDL during preparation and storage, ${ }^{27}$ and therefore the anti-oxPAPC test is more reliable and readily standardised than the anti-oxLDL test. A raised concentration of anti-oxPAPC antibodies was significantly associated with atherosclerotic manifestations. ${ }^{27}$ We observed a significant reduction of anti-oxPAPC antibody levels

Table 5 Multiple logistic regression analysis (best model) of factors associated with carotid lesions in the 78 patients with SLE

\begin{tabular}{|c|c|c|c|}
\hline Variables & Odds ratio & $95 \% \mathrm{Cl}$ & p Value \\
\hline \multicolumn{4}{|c|}{ Dependent variable: carotid plaque (McFaden's $\rho^{2}=0.412 ; \mathrm{p}<0.0005$ ) } \\
\hline Age (years) & 1.17 & 1.07 to 1.29 & 0.001 \\
\hline PDN cumulative dose (g) & 1.09 & 1.03 to 1.16 & 0.002 \\
\hline Anti-oxPAPC (U/ml) at T2 & 1.06 & 0.98 to 1.15 & 0.117 \\
\hline \multicolumn{4}{|c|}{$\begin{array}{l}\text { Dependent variable: thickened intima (McFaden's } \rho^{2}=0.260 ; p<0.0005 \text { ) } \\
\text { Independent variables }\end{array}$} \\
\hline Age (years) & 1.09 & 1.02 to 1.17 & 0.007 \\
\hline PDN cumulative dose (g) & 1.03 & 0.99 to 1.06 & 0.121 \\
\hline Anti-oxPAPC (U/ml) at T2 & 1.05 & 0.97 to 1.14 & 0.219 \\
\hline Absence of hypertension & 0.52 & 0.24 to 0.98 & 0.046 \\
\hline
\end{tabular}

Table 6 Multiple linear regression analysis (best model) of factors associated with intimamedia thickness (IMT) of the carotid artery in the 78 patients with SLE

\begin{tabular}{|c|c|c|c|}
\hline Variables & $\begin{array}{l}\text { Standard regression } \\
\text { coefficient }\end{array}$ & $\mathbf{F}$ & p Value \\
\hline \multicolumn{4}{|l|}{$\begin{array}{l}\text { Dependent variable: M-IMT } \\
\text { Independent variables }\end{array}$} \\
\hline Age (years) & 0.41 & 21.50 & $<0.0005$ \\
\hline Anti-oxPAPC (U/ml) at T2 & 0.35 & 15.32 & $<0.0005$ \\
\hline PDN cumulative dose (g) & 0.20 & 4.06 & 0.047 \\
\hline $\begin{array}{l}\text { Renal disease at baseline } \\
R^{2}=0.408\end{array}$ & 0.17 & 2.99 & 0.088 \\
\hline \multicolumn{4}{|l|}{$\begin{array}{l}\text { Dependent variable: m-IMT } \\
\text { Independent variables }\end{array}$} \\
\hline Age (years) & 0.53 & 34.34 & $<0.0005$ \\
\hline Hypertension & 0.25 & 8.40 & 0.005 \\
\hline $\begin{array}{l}\text { Anti-oxPAPC }(\mathrm{U} / \mathrm{ml}) \text { at } \mathrm{T} 2 \\
\mathrm{R}^{2}=0.483\end{array}$ & 0.20 & 6.19 & 0.028 \\
\hline
\end{tabular}


throughout the follow up, probably as the result of treatment. Anti-oxPAPC levels were not associated with carotid abnormalities in multivariate logistic analysis either at baseline or at the time of ultrasound examination. However, anti-oxPAPC levels at T2 were correlated with increased M-IMT and m-IMT in the multivariate linear regression model.

Another antibody system which plays a part in atherogenesis is the anti-HSP65. High titres of anti-HSP60/65 antibodies were associated with atherosclerotic lesions in the carotid $^{35}$ as well as in the coronary vessels ${ }^{36} 37$ in populations without SLE. As for the anti-oxPAPC antibodies, we noted a reduction of anti-HSP65 titre throughout the follow up, but in contrast with anti-oxPAPC, we did not find any relationship between anti-HSP65 titre and carotid abnormalities in patients with SLE. Possibly, in patients with SLE, disease treatment (especially immunosuppressant drugs) reduces the potential atherogenic role of anti-HSP65 antibodies.

Antiphospholipid antibodies (aPL) are associated with arterial and venous thrombosis and are detected in the serum of about $50 \%$ of patients with SLE. ${ }^{38}$ Their role in predicting CVD is controversial. ${ }^{39}$ Nevertheless, it has been recently postulated that aPL, such as anti- $\beta_{2}$ GPI, may contribute to the formation of atherosclerotic lesions. ${ }^{40}$ In our study, anti- $\beta_{2}$ GPI as well as aCL and LA did not seem to predispose to the development of carotid lesions. This result, in keeping with data observed by others, ${ }^{89}$ may be due to the wide use of low dose aspirin or anticoagulants in patients with high risk for aPL manifestations or with definite antiphospholipid syndrome.

Taking into account all the data for the new immunological and inflammatory parameters, we suggest that in SLE they do not have the same predictive value as seen in other populations as they may be masked by some disease related features.

In conclusion, we identified some non-traditional predictors for atherosclerosis in patients with SLE. These features are indicative of a more severe disease like prednisone cumulative intake, renal disease, and active disease at baseline. Moreover, we confirmed the role of some traditional risk factors for atherosclerosis in patients with SLE, such as age and hypertension. The new immunological and inflammatory markers do not seem to have a role in predicting atherosclerosis in SLE.

Therefore, maximum effort should be made to treat lupus glomerulonephritis adequately using the lowest possible dosage of corticosteroids associated with corticosteroid sparing therapy and at the same time to manage renal complications, first of all hypertension, as quickly as possible.

\section{ACKNOWLEDGEMENTS}

This work was supported by "Ministero Italiano dell'Università e della Ricerca Scientifica e Tecnologica" (60\% 2001: project 503), and by Incumbent of the Laura Schwarz-Kipp Chair for Research of Autoimmune Diseases, Tel-Aviv University

\footnotetext{
Authors' affiliations

A Doria, P F Gambari, A Ghirardello, S Corbanese, S Zampieri, L laccarino, S Todesco, Division of Rheumatology, Department of Medical and Surgical Science, University of Padova, Italy

Y Shoenfeld, B Gilburd, Y Sherer, Department of Medicine B, Centre for Autoimmune Diseases, Sheba Medical Centre, Tel-Hashomer, Sackler Faculty of Medicine, Tel-Aviv University, Israel

R Wu, M Patnaik, J B Peter, Specialty Laboratories, Santa Monica, CA, USA

M Puato, E Favaretto, P Pauletto, Department of Clinical and

Experimental Medicine, University of Padova, Italy
}

\section{REFERENCES}

1 Bulkley BH, Roberts WC. The heart in SLE and the changes induced in it by corticosteroid therapy: a study of 36 necroscopy cases. Am J Med 1975;53:243-64.

2 Urowitz MB, Bookman AA, Koehler BE, Gordon DA, Smythe HA, Ogryzlo MA. The bimodal mortality pattern of SLE. Am J Med 1976;60:221-5.

3 Esdaile JM, Abrahamowicz M, Grodzicky T, Li Y, Panaritis C, du Berger R, ef al. Traditional Framingham risk factors fail to fully account for accelerated atherosclerosis in systemic lupus erythematosus. Arthritis Rheum 2001;44:2231-7.

4 Petri M, Perez-Gutthann S, Spence D, Hochberg MC. Risk factors for coronary artery disease in patients with systemic lupus erythematosus. Am J Med 1992;93:513-19.

5 Gladman DD, Urowitz MB. Morbidity in systemic lupus erythematosus. J Rheumatol 1987;14:223-6.

6 Manzi S, Meilahn EN, Rairie JE, Conte CG, Medsger TA, JansenMcWilliams $L$, et al. Age-specific incidence rates of myocardial infarction and angina in women with systemic lupus erythematosus: comparison with the Framingham Study. Am J Epidemiol 1997; 145:408-15.

7 Manzi S, Selzer F, Sutton-Tyrrel K, Fitzgerald SG, Rairie JE, Tracy RP, et al. Prevalence and risk factors of carotid plaque in women with systemic lupus erythematosus. Arthritis Rheum 1999;42:51-60.

8 Roman MJ, Salmon JE, Sobel R, Lockshin MD, Sammaritano L, Schwartz JE, et al. Prevalence and relation to risk factors of carotid atherosclerosis and left ventricular hypertrophy in systemic lupus erythematosus and antiphospholipid antibody syndrome. Am J Cardiol 2001;87:663-6.

9 Svenungsson E, Jensen-Urstad K, Heimbürger M, Silveira A, Hamsten A, de Faire $U$, et al. Risk factors for cardiovascular disease in systemic lupus erythematosus. Circulation 2001;104:1887-93.

10 Vlachoyiannopoulos PG, Kanellopoulos PG, loannidis JPA, Tektonidou MG, Mastorakou I, Moustopoulos HM. Atherosclerosis in premenopausal women with antiphospholipid syndrome and systemic lupus erythematosus: a controlled study. Clin Exp Rheumatol 2002;20:265.

11 Rahman P, Urowitz MB, Galdman DD, Bruce IN, Genest J. Contribution of traditional risk factors to coronary artery disease in patients with systemic lupus erythematosus. J Rheumatol 1999;26:2363-8.

12 Bruce IN, Urowitz MB, Galdman DD, Hallett DC. Natural history of hypercholesterolemia in systemic lupus erythematosus. I Rheumatol 1999;26:2137-43.

13 Bruce IN, Galdman DD, Urowitz MB. Premature atherosclerosis in systemic lupus erythematosus. Rheum Dis Clin North Am 2000;26:257-78.

14 Ward MM. Premature morbidity from cardiovascular and cerebrovascular diseases in women with systemic lupus erythematosus. Arthritis Rheum 1999;42:338-46.

15 Shoenfeld $Y$, Harats D, Wick G, eds. Atherosclerosis and autoimmunity. Amsterdam, The Netherlands: Elsevier, 2001.

16 Khamashta M, Hughes G, eds. Special issue: Accelerated atheroma-leads from lupus. Lupus 2000;9:159-231.

17 Ridker PM. High-sensitivity C-reactive protein: potential adjunct for global risk assessment in the primary prevention of cardiovascular disease. Circulation 2001;103:1813-8.

18 George J, Afek A, Gilburd B, Harats D, Shoenfeld Y. Autoimmunity in atherosclerosis: lesson from experimental models. Lupus 2000:9:223-7.

19 Lockshin MD, Salmon JE, Roman MJ. Atherosclerosis and lupus: a work in progress. Arthritis Rheum 2001;44:2215-17.

20 Li R, Cai J, Tegeler C, Sorlie P, Metcalf PA, Heiss G. Reproducibility of extracranial carotid atherosclerotic lesion assessed by B-mode ultrasound: the Artherosclerosis Risk in Communities Study. Ultrasound Med Biol 1996:22:791-9

21 O'Leary DH, Polak JF, Kronmal RA, Manolio TA, Burke GL, Wolfson SK for the Cardiovascular Health Study Collaborative Research Group. Carotid-artery intima and media thickness as a risk factor for myocardial infarction and stroke in older adults. Cardiovascular Health Study Collaborative Research Group. N Eng J Med 1999;340:14-22.

22 Tan EM, Cohen AS, Fries JF, Masi AT, McShane DJ, Rothfield NF, et al. The 1982 revised criteria for the classification of systemic lupus erythematosus. Arthritis Rheum 1982;25:1271-7.

23 Harris EN. Antiphospholipid antibodies (Annotation). Br J Haematol 1990;74:1-9.

24 Vitali C, Bencivelli W, Isenberg DA, Smolen JS, Snaith ML, Sciuto M, et al. Disease activity in systemic lupus erythematosus: report of the Consensus Study Group of the European Workshop for Rheumatology Research. II Identification of the variables indicative of disease activity and their use in the development of an activity score. The European Consensus Study Group for Disease Activity in SLE. Clin Exp Rheumatol 1992;10:541-7.

25 Gladman D, Ginzler E, Goldsmith C, Fortin P, Liang M, Urowitz M, et al. The development and initial validation of the Systemic Lupus International Collaborating Clinics/American College of Rheumatology Damage Index for systemic lupus erythematosus. Arthritis Rheum 1996:39:363-9.

26 Hörkkö S, Bird DA, Miller E, Itabe H, Leitinger N, Sbbanagounder G, et al. Monoclonal autoantibodies specific for oxidized phospholipids or oxidized phospholipids-protein adducts inhibit macrophage uptake of oxidized lowdensity lipoproteins. J Clin Invest 1999;103:117-28.

27 Wu R. Autoantibodies against oxidized palmitoyl arachidonoyl phosphocholine in atherosclerosis. In: Shoenfeld Y, Harats D, Wick G, , eds. Atherosclerosis and autoimmunity. Amsterdam, the Netherlands: Elsevier, 2001:151-9. 
28 Pauletto P, Palatini P, Da Ros S, Pagliara V, Santipolo N, Baccilieri S, et al. Factors underlying the increase in carotid intima-media thickness in borderline hypertensives. Arterioscler Thromb Vasc Biol 1999;19:1231-7.

29 Howard G, Sharrett AR, Heiss G, Evans GW, Chambless LE, Riley WA, et al Carotid artery intima-media thickness distribution in general populations as evaluated by B-mode ultrasound. ARIC Investigators. Stroke 1993;24:1297-304.

30 Borhani NO, Mercuri M, Borhani PA, Buckalew VM, Canossa-Terris M, Carr AA, et al. Final outcome results of the Multicenter Isradipine Diuretic Atherosclerosis Study (MIDAS). A randomized controlled trial. JAMA 1996;276:785-91.

31 Falaschi F, Revelli A, Martignoni A, Migliavacca A, Sartori M, Pistorio G, et al. Nephrotic-range proteinuria, the major risk factor for early atherosclerosis in juvenile-onset systemic lupus erythematosus. Arthritis Rheum 2000;43:1405-9.

32 ter Borg EJ, Horst G, Limburg PC, van Rijswijk Mh, Kallemberg CG. C-reactive protein levels during exacerbation and infection in systemic lupus erythematosus: a prospective longitudinal study. J Rheumatol 1990;17:1642-8.

33 Hörkkö S, Olee T, Mo L, Branch DW, Woods VL, Palinski W, et al. Anticardiolipin antibodies from patients with the antiphospholipid antibody syndrome recognize epitopes in both beta(2)-glycoprotein I and oxidized lowdensity lipoprotein. Circulation 2001;103:941-6.

34 Watson AD, Leitinger N, Navab M, Faull KF, Hörkkö S, Witztum JL, et al. Structural identification by mass spectrometry of oxidized phospholipids in minimally oxidized low density lipoprotein that induce monocyte/endothelial interactions and evidence for their presence in vivo. J Biol Chem 1997;272:13597-607.

35 Xu Q, Willeit J, Marosi M, Kleindienst R, Oberhollenzer F, Kiechl S, et al. Association of serum antibodies to heat-shock protein 65 with carotid atherosclerosis. Lancet 1993;341:255-59.

36 Hoppichler F, Lechleitner M, Traweger C, Schett G, Dzien A, Sturm W, et al. Changes of serum antibodies to heat-shock protein 65 in coronary heart disease and acute myocardial infarction. Atherosclerosis 1996;126:333-8.

37 Birnie DH, Holme ER, McKay IC, Hood S, McColl KE, Hillis WS. Association between antibodies to heat-shock protein 65 and coronary atherosclerosis. Possible mechanism of action of Helicobacter pylori and other bacterial infections in increasing cardiovascular risk. Eur Heart J 1998;19:387-94.

38 Ghirardello A, Doria A, Ruffatti A, Rigoli A, Vesco P, Calligaro A, et al. Antiphospholipid antibodies (aPL) in systemic lupus erythematosus. Are they specific tools for the diagnosis of aPL syndrome? Ann Rheum Dis 1994;53:140-2

39 Phadke KV, Philliphs RA, Clarke DT, Jones M, Naish P, Carson P. Anticardiolipin antibodies in ischemic heart disease: marker or myth? $\mathrm{Br}$ Heart J 1993;69:391-4.

40 George J, Blank M, Levy Y, Meroni PL, Damianovich M, Tincani A, et al. Differential effects of anti-beta2-glycoprotein I antibodies on endothelial cells and on the manifestations of experimental antiphosphpolipid syndrome. Circulation 1998;97:900-6.

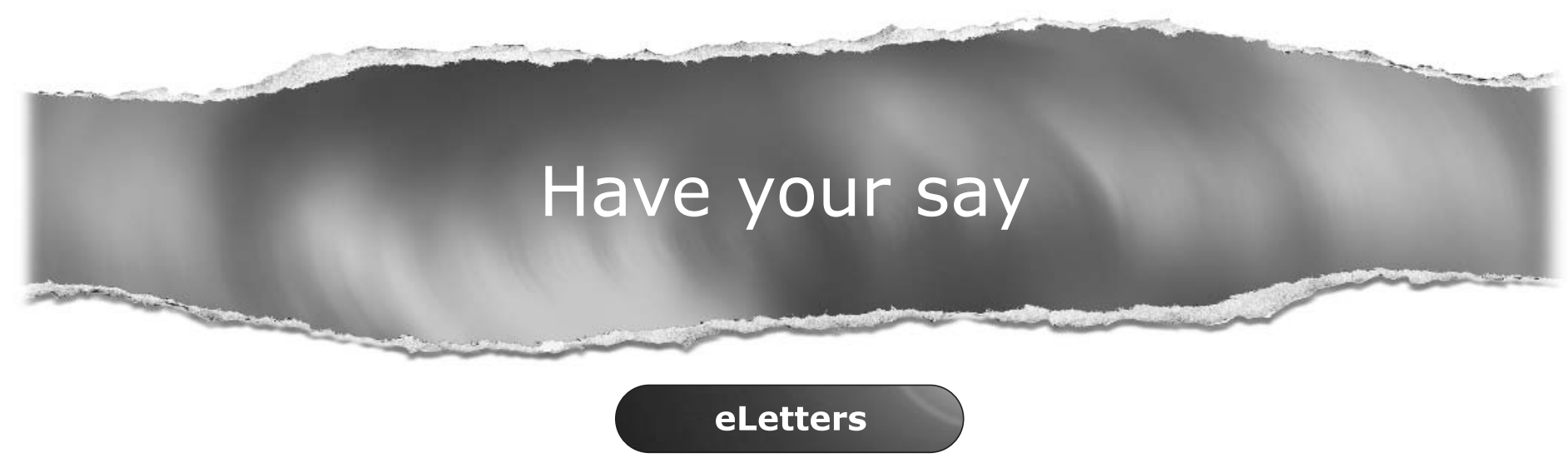

If you wish to comment on any article published in Annals of the Rheumatic Diseases you can send an eLetter using the eLetters link at the beginning of each article. Your response will be posted on Annals of the Rheumatic Diseases online within a few days of receipt (subject to editorial screening).

\section{www.annrheumdis.com}

